\title{
A telemetric method for measuring and recording head rotations in human infants
}

\author{
B. E. McKENZIE and K. H. SACK, \\ MONASH UNIVERSITY, Clayton, \\ Victoria 3168, A ustralia
}

A simple and reliable apparatus for recording directional head movements of infants is described. The technique permits unrestricted movement and avoids distress associated with mechanical head harnesses.

Recent conditioning studies with human neonates and young infants have employed modifications of Siqueland's (1964) technique to record head movements (Siqueland \& Lipsitt, 1966; Caron, 1967; Papousek, 1967). Usually a head harness is attached to the infant and movements are recorded by a flexible shaft connected to a potentiometer circuit. Preliminary work suggested that this arrangement sometimes caused distress resulting in a high $S$ rejection rate. Distress has also been reported by Levison and Levison (1967).

In our work, a technique was required that would record automatically degree and direction of head rotation without restricting freedom of movement and without obstructing the visual field. It was also considered necessary to avoid differential tactile stimulation of the face since this might serve as a stimulus to head movement.

Movement of the infant's head was monitored and recorded using a telemetric system. An oscillator driving a loop antenna $(2 \mathrm{~cm}$ diam) was attached to the forehead of the infant (Fig. 1). The oscillator was biased to generate bursts of $600 \mathrm{kHz}$ at a repetition rate of $2 \mathrm{kHz}$. This effectively produced a modulated signal with a broad frequency spectrum. The circuit diagram is shown in Fig. 2. Commercial portable radio receivers (Philips, Model RL 270) placed symmetrically on either side of an enclosed crib served to detect the signal from the oscillator. The receiver audio output varied as an inverse function of the distance between the oscillator loop and the receiver antenna. The audio output from each earphone jack was rectified and filtered, and the resultant dc signals were connected differentially to a chart recorder (Both, Model R 12).

Fig. 1. Position of the oscillator in relation to the rod antennae of the two receivers.
The current drain from the 1.3-V mercury battery was 100 microamperes. Two turns of the loop antenna gave optimal signal-noise ratio with the detectors placed $40 \mathrm{~cm}$ either side of the oscillator. More than two tums resulted in excessive coupling, which caused the automatic volume control of the receivers to function and reduce the sensitivity of the system. The components and a clip for the battery were encapsulated with epoxy resin. The total weight was $5 \mathrm{~g}$.

The transmitter was firmly taped to the infant's forehead (Fig. 1) with Micropore surgical tape (No. 1530), which is easily removed from the skin and is nonirritant. The plane of the loop was directed transversely in the line joining the centers of the rod antennae of the two receivers (Fig. 1). The receivers were tuned to the oscillator, and their volume controls set to a position that had been found to give adequate sensitivity without the receivers' overloading. The earphone plugs were then inserted and slight volume readjustments made to center the pen with the infant's head in the midline of the crib and to give equal deflections for standard displacement in either direction.

Using a chart speed of $1 \mathrm{~mm} / \mathrm{sec}$, the system is sensitive to head rotations of $5 \mathrm{deg}$, which results in a pen deflection of $5 \mathrm{~mm}$. The system does not distinguish lateral displacement from rotational displacement and is almost unaffected by longitudinal movements of the infant. Rotation of the oscillator loop about its vertical axis has only a slight effect on the system sensitivity for moderate rotations. Changes in resting posture of the head may result in a shift of the recorder base line. However, displacements from this base line are readily detectable. The system sensitivity appears to remain constant during experimental sessions of approximately $30 \mathrm{~min}$ and is recalibrated for each subsequent session. The accuracy of measurement of degree of head turns depends not only on the stability and precision of the recording system, but also on individual differences in types of head movements between and within Ss.

This method is currently being used in a study of pattern discrimination in infants between 6 and 12 weeks of age. A head turn is defined here as any lateral movement from the central position with head upright that leads to a deflection of $10 \mathrm{~mm}$ or more on the recorder, or a similar movement from a base line that has been maintained for at least $5 \mathrm{sec}$. These movements approximate a rotation of $10 \mathrm{deg}$ or more, or a lateral displacement of $2.5 \mathrm{~cm}$.

The apparatus is simple and inexpensive to construct and is useful in experiments where control of the visual field is required without leading to distress and discomfort in infant Ss.

\section{REFERENCES}

CARON, R. F. Visual reinforcement of head-tuming in young infants. Joumal of Experimental Child Psychology, 1967, 5, 489-511.

LEVISON, C. A., \& LEVISON, P. K. Operant conditioning of head turning for visual reinforcement in three-month infants. Psychonomic Science, 1967, 8, 529-530.

PAPOUSEK, $H$. Conditioning during early postnatal development. In Y. Brackbill and G.

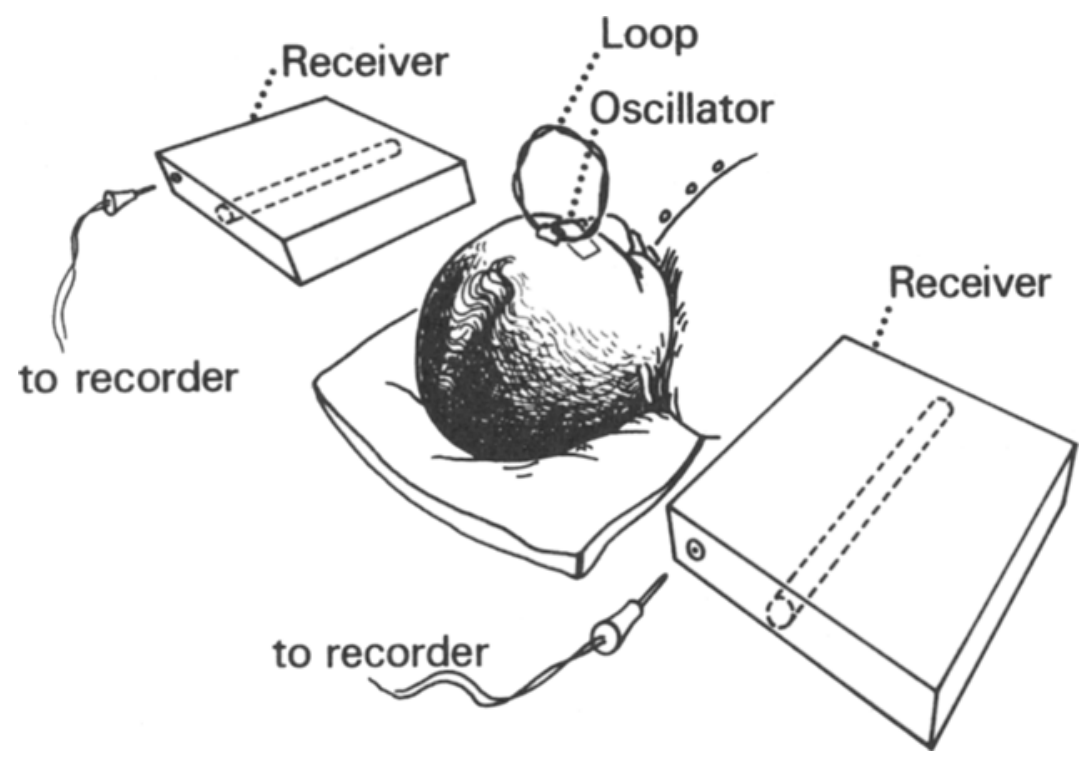




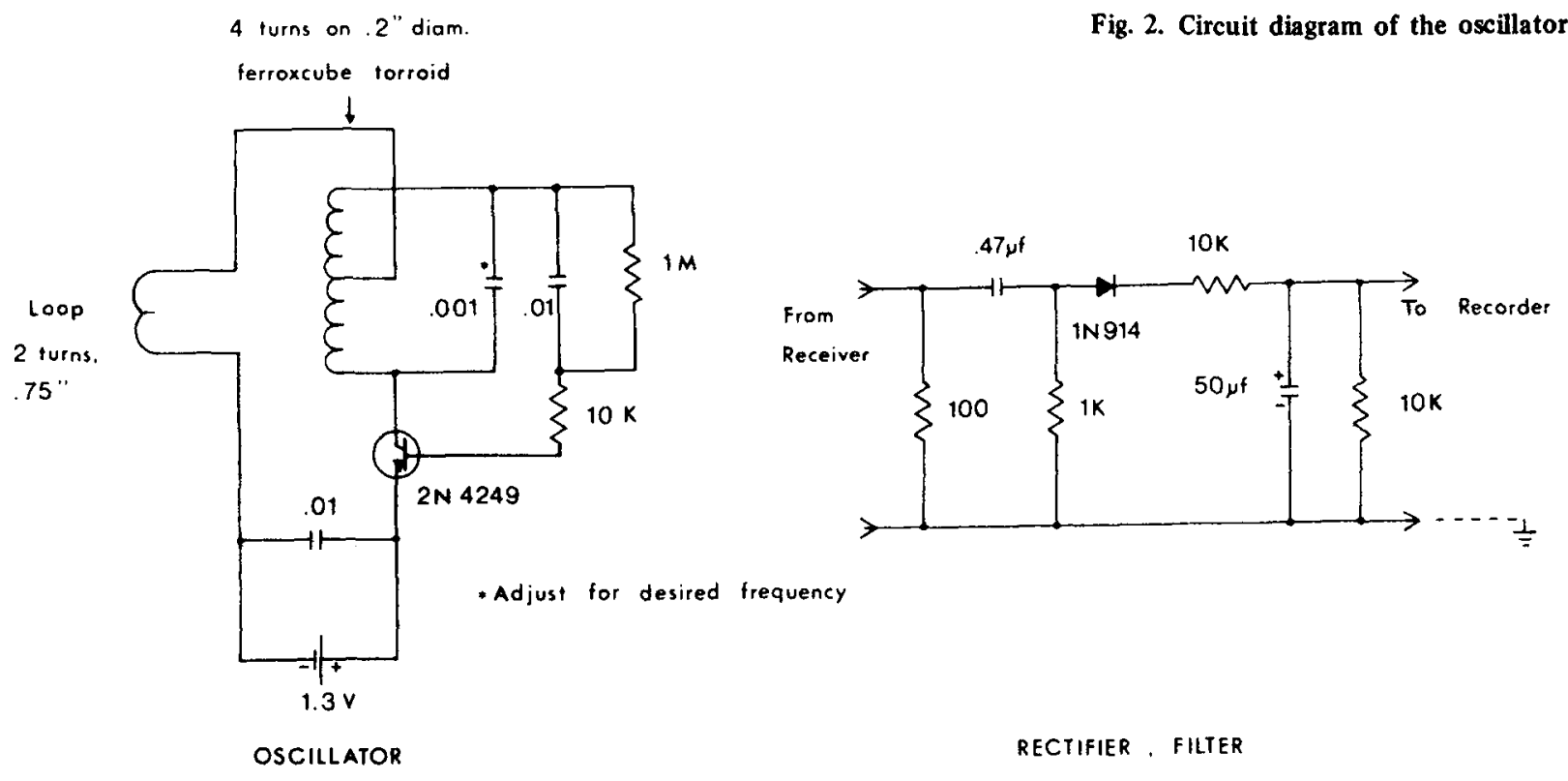

G. Thompson (Eds.), Behavior in infancy and early childhood. New York: Free Press, 1967. SIQUELAND, E. R. Operant conditioning of head-turning in four-month infants.

Psychonomic Science, 1964, 1, 223-224.

SIQUELAND, E. R., \& LIPSITT, L. P.
Conditioned head-turning in human new-borns. Journal of Experimental Child Psychology, 1966, 3, 356-376. 